\title{
Extension of Water Flowing Fractured Zone during Coal Seams Mining in No.1 Mine of Tashendian Area
}

\author{
Qinghai Li \\ College of Mining and Safety \\ Engineering \\ Shandong University of Science and \\ Technology \\ Qingdao, China \\ liqinghai@sdust.edu.cn \\ Jingkai Li \\ College of Mining and Safety \\ Engineering \\ Shandong University of Science and \\ Technology \\ Qingdao, China \\ LJK_0801@163.com
}

\author{
Tongbin Zhao \\ College of Mining and Safety \\ Engineering \\ Shandong University of Science and \\ Technology \\ Qingdao, China \\ ztbwh2001@163.com
}

\author{
Zhen $\mathrm{Li}$ \\ College of Mining and Safety \\ Engineering \\ Shandong University of Science and \\ Technology \\ Qingdao, China \\ 767312022@qq.com
}

\begin{abstract}
In coal seams mining in No. 1 mine of Tashendian area, three methods of theoretical analysis, UDEC numerical simulation, and physical simulation test were used in this research to analyze the extension height of water flowing fractured zone and the height of waterproof coal (rock) pillar. By calculation, it was obtained that, after each coal seam mined out, the height of water flowing fractured zone is about $33.7 \mathrm{~m}$ above 8-1 \# coal seam, and the size of waterproof coal (rock) pillar greater than $44.06 \mathrm{~m}$ was reasonable; after upper and lower groups coal seam mined out, the height of water flowing fractured zone is about $81 \mathrm{~m}$ above 8-1\# coal seam, and the size of waterproof coal (rock) pillar greater than $91.36 \mathrm{~m}$ was reasonable; after all coal seams mined out simultaneously, the height of water flowing fractured zone is about $95.1 \mathrm{~m}$ above 8-1 \# coal seam, and the size of waterproof coal (rock) pillar greater than $105.46 \mathrm{~m}$ was reasonable. By numerical simulation, it was obtained that, after upper and lower groups coal seam mined out, the height of water flowing fractured zone is about 46.0 $\mathrm{m}$ above 8-1 \# coal seam, and the size of waterproof coal (rock) pillar greater than $56.36 \mathrm{~m}$ was reasonable; after all coal seams mined out simultaneously, the height of water flowing fractured zone is about $76.0 \mathrm{~m}$ above 8-1\# coal seam, and the size of waterproof coal (rock) pillar greater than $86.36 \mathrm{~m}$ was reasonable; By physical simulation, it was obtained that, after upper and lower groups coal seam mined out, the height of water flowing fractured zone is about $40.0 \mathrm{~m}$ above 8-1 \# coal seam. And the waterproof coal (rock) pillar was about $70.0 \mathrm{~m}$ between and the aquifer. In situ production, each coal seam was mined out orderly.
\end{abstract}

Keywords-coal seams, water flowing fractured zone, waterproof coal (rock) pillar, theoretical analysis, numerical simulation, physical simulation

\section{INTRODUCTION}

As the main coal-producing area in China, there was relatively weak ecological environment in the western region of China. If fissures induced by coal mining extend to the aquifer, it will not only threaten the producing of coal mines, but will also lead to a significant declining of underground water levels, which will lead to plants dead, crops dry, and areas desertification. The effects will be even greater in Xinjiang, where the ecological environment is more fragile.

The No.1 mine of Tashendian area is located in the city of Korla, Xinjiang Uygur Autonomous Region and has a designed production capacity of $1.2 \mathrm{Mt} / \mathrm{a}$. There are 7 coal seams in this area, most of which are partially recoverable. 7 coal seams are numbered as $13 \#, 12 \#, 10$ \#, 9 \#, 8-3 \#, 8-2 \#, and 8-1 \# from bottom to top, with a total thickness of $21.92 \mathrm{~m}$. The angle of each coal seam is between $4^{\circ}-24^{\circ}$, which belongs to nearly horizontal inclined range. There is an aquifer $97.6 \mathrm{~m}$ above 8-1 \# coal seam in Tertiary Oligocene Miocene Taoshuyuan formation. The thickness of aquifer reaches 64.91 $158.00 \mathrm{~m}(116.48 \mathrm{~m}$ in average). And the water pressure of aquifer reaches $0.44 \mathrm{MPa}$. The permeability coefficient of aquifer is $0.0469-0.2288 \mathrm{~m} / \mathrm{d}$. Thus, the acquirer belongs to a medium-rich water source and is the main water filling source during coal mining.

Peng [1], Meng [2], Wang [3], Liu [4] et al. adopted the theoretical analysis method to obtain different calculation formulas of waterproof protection coal pillar. Li [5], Liu [6], Yin [7], Chen [8], He [9], Yang [10] used numerical software $\mathrm{UDEC}^{2 \mathrm{D}}$, FLAC ${ }^{3 \mathrm{D}}$ and RFPA $^{2 \mathrm{D}}$ to simulate and analyze the propagation of water flowing fractured zone (short as WFFZ) and the size of waterproof coal pillars under different geological conditions. Jia [11], $\mathrm{Xu}$ et al. [12] have studied the propagation of WFFZ by means of physical simulation experiments. At the same time, Zhu et al. [13] put forward the process of rock failure under the

coupling of fluid and solid. Based on properties analysis 
on engineering strata, Tu et al. [14] has studied the maximum height of the WFFZ under different mining ratios. Ma et al. [15] analyzed the hydraulic conductivity mechanism in fractured zone. Xu [16] put forward the concept of water insulation thickness. Based on the theory of four zones in roof, Shi et al. [17] deduced the calculation formula of WFFZ, which included factors of mining thickness, mining depth, working face span, rock mechanical properties, strata characteristics and water pressure in aquifer. Li et al. [18] concluded that mining depth, coal seam's dip angle, thickness, hardness, structure were the main factors affecting the height of WFFZ. Based on energy conservation, Zhang et al. [19] established the approximate relationship among the height of fractured zone, mining parameters and the characteristics of overlying strata. By fuzzy clustering analysis method, Yang et al. [20] analyzed the height of fractured zone in working face. Li et al. [21] studied the adaptability of underground reservoir based on the height of WFFZ. With method of vector machine, Zhang et al. [22] set up a height prediction model for WFFZ. Based on key strata analyzing, $\mathrm{Xu}$ et al. [23] proposed a new method for predicting the height of WFFZ. Gao et al. [24] analyzed the height of the fractured zone using traditional empirical formula. Sun et al. [25] obtained the spatial position of WFFZ using ESG microseismic monitoring system.

The WFFZ is located above the caving zone. It is significant to study the extension height of the WFFZ to prevent inrushing during mining. In view of the existence of aquifer in Tertiary Oligocene Miocene Taoshuyuan formation, in order to prevent the influence of aquifer during 7 coal seams mining, theoretical analysis, UDEC ${ }^{2 \mathrm{D}}$ numerical simulation and physical simulation were used to analyze the extension of WFFZ. Based on this, for 8-1 \#, 8-2 \#, 8-3 \#, and 9 \# coal seams, reasonable coal (rock) pillar sizes are designed.

\section{THEORETICAL ANALYSIS ON EXTENSION HEIGHT OF WFFZ}

\section{A. Strata in Tashendian area}

From the preliminary design report of No. 1 Mine of Tashendian Area, strata parameters are decided and shown in Table 1. According to Table 1, it was determined that the unidirectional compressive strength of most strata is in the range of $10-30 \mathrm{MPa}$. The engineering geological conditions belong to II medium category.

\section{B. Calculation for the height of WFFZ}

a) WFFZ Formula for the height of WFFZ. According to the theory of three overlying zones, the WFFZ refers to the sum of the caving zone and fractured zone of the overburden strata in the mined area. When strength of overburden strata are hard, medium hard, weak and very weak, the maximum height of the WFFZ can be calculated according to two empirical formulas in Table 2 [26].

According to the mechanics parameters of coal seams' roof and floor, it can be seen that for saturated uniaxial compressive strength, only siltstone in 9 \# coal seam floor and fine sandstone in 13 \# coal seam roof exceeds $40 \mathrm{MPa}$, and other strata are less than $40 \mathrm{MPa}$. It is decided that the strata in this mining field belongs to the range of medium-hard. Therefore, the WFFZ can be calculated according to formulas of medium hard strata.

TABle 1. StRATA MECHANICAL PARAMETERS

\begin{tabular}{|c|c|c|c|c|c|c|c|c|c|}
\hline \multirow{2}{*}{ Strata } & \multirow{2}{*}{$\begin{array}{c}\text { Thickness } \\
\text { /m }\end{array}$} & \multirow{2}{*}{$\begin{array}{c}\text { Bulk } \\
\text { density } \\
/ \mathrm{g} \cdot \mathrm{cm}^{-3}\end{array}$} & \multirow{2}{*}{$\begin{array}{c}\text { Water } \\
\text { content } \\
/(\%)\end{array}$} & \multicolumn{2}{|c|}{$\begin{array}{c}\text { Uniaxial compressive } \\
\text { strength /MPa }\end{array}$} & \multirow{2}{*}{$\begin{array}{c}\text { Tensile strength } \\
\text { /MPa }\end{array}$} & \multicolumn{2}{|c|}{ Shear strength /MPa } & \multirow{2}{*}{$\begin{array}{l}\text { Softening } \\
\text { coefficient }\end{array}$} \\
\hline & & & & Saturated & Dry & & Saturated & Dry & \\
\hline Aquifer & 117 & 2.43 & 6 & 18.13 & 40.53 & 1.04 & 5.32 & 10.43 & 0.48 \\
\hline Mudstone & 8 & 2.32 & 1 & 17.8 & 58.7 & 0.5 & 4.94 & 14.55 & 0.43 \\
\hline Siltstone & 50 & 2.43 & 0.47 & 21.13 & 43.53 & 2.04 & 6.32 & 13.43 & 0.5 \\
\hline Fine sandstone & 39.6 & 2.47 & 0.48 & 19.68 & 52.85 & 2.83 & 6.2 & 16.43 & 0.36 \\
\hline 8-1\# Coal & 1.4 & 1.47 & 0.5 & 3.5 & 12.8 & 3.6 & 2.6 & 3.2 & 0.32 \\
\hline Fine sandstone & 13.6 & 2.32 & 1 & 17.8 & 58.7 & 0.5 & 4.94 & 14.55 & 0.43 \\
\hline 8-2\# Coal & 3.4 & 1.47 & 0.5 & 3.5 & 12.8 & 3.6 & 2.6 & 3.2 & 0.32 \\
\hline Siltstone & 8 & 2.43 & 0.47 & 21.13 & 43.53 & 2.04 & 6.32 & 13.43 & 0.5 \\
\hline 8-3 Coal & 1 & 1.47 & 0.5 & 3.5 & 12.8 & 3.6 & 2.6 & 3.2 & 0.32 \\
\hline Siltstone & 34.9 & 2.39 & 0.42 & 27.01 & 53.84 & 1.53 & 6.14 & 13.2 & 0.37 \\
\hline 9\# Coal & 2.1 & 1.47 & 0.5 & 3.5 & 12.8 & 3.6 & 2.6 & 3.2 & 0.32 \\
\hline Gravel rock & 22.4 & 2.33 & 0.15 & 19.1 & 33.6 & 0.96 & 5.88 & 11.8 & 0.56 \\
\hline 10\# Coal & 4.6 & 1.47 & 0.5 & 3.5 & 12.8 & 3.6 & 2.6 & 3.2 & 0.32 \\
\hline Gravel rock & 124.6 & 2.46 & 0.58 & 23.12 & 55.65 & 1.71 & 7.01 & 15.53 & 0.48 \\
\hline 12\# Coal & 2.4 & 1.47 & 0.5 & 3.5 & 12.8 & 3.6 & 2.6 & 3.2 & 0.32 \\
\hline Gravel rock & 30 & 2.44 & 0.3 & 24.9 & 64.5 & 1.5 & 7 & 20.3 & 0.4 \\
\hline 13\# Coal & 3.2 & 1.47 & 0.5 & 3.5 & 12.8 & 3.6 & 2.6 & 3.2 & 0.32 \\
\hline Coarse sandstone & 73.8 & 2.48 & 0.4 & 28.4 & 48.8 & 3.82 & 8.89 & 18.9 & 0.58 \\
\hline
\end{tabular}


TABLE2. Formula FOR THE HEIGHT OF WFFZ (m)

\begin{tabular}{|c|l|l|}
\hline $\begin{array}{c}\text { Lithology of } \\
\text { overburden strata } \\
\text { (Uniaxial } \\
\text { compressive } \\
\text { strength /MPa) }\end{array}$ & Formula One & Formula Two \\
\hline Hard (40 80) & & \\
\hline $\begin{array}{c}\text { Medium hard } \\
(20 \sim 40)\end{array}$ & & \\
\hline $\begin{array}{c}\text { Weak }(10 \sim 20) \\
\text { Very weak }(<10)\end{array}$ & & \\
\hline
\end{tabular}

Note 1): The applicable range of the empirical formula in above table is that the single-layer mining thickness is $1-3 \mathrm{~m}$, and the cumulative mining thickness is less than $15 \mathrm{~m}$.

According to mining regulation rules [26], during closer coal seams mining, when the vertical distance $h$ between the upper and lower seams is greater than the height of the caving zone produced by the lower seam mining (Fig. 1), there is little effect of lower seam caving zone on upper seam. The height of the WFFZ and the height of the caving zone can be calculated according to the thicknesses of coal seams respectively. The highest value is regarded as the WFFZ of two seams. Referring to the production experience of nearby coal mines, coal seams mining in No.1 mine of Tashendian area can be calculated according to this situation.

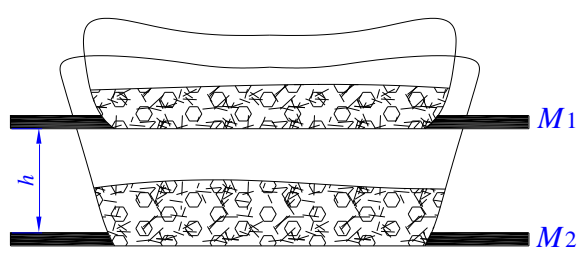

Fig.1. Height of caving zone and WFFZ during close coal seams mining

b) Calculation programs. Combined with the occurrence of coal seams in the preliminary design report, it is determined that the height of the WFFZ is calculated according to the following three programs.

Program 1: The height of WFFZ is calculated according to each coal seam mined out orderly.

Program 2: The height of WFFZ is calculated according to upper group and lower group mined out orderly. Because of large distance $(124.6 \mathrm{~m})$ between 10 \# and 12 \# coal seam, 7 coal seams can be divided into two groups, lower group (12 \# and 13 \# coal seams) and upper group (8-1 \#, 8-2 \#, 8-3 \#, 9 \#, and 10 \# coal seams). The total thickness of the lower group coal seam is $5.6 \mathrm{~m}$, and the total thickness of the upper group coal seam is $12.6 \mathrm{~m}$

Program 3: The height of WFFZ is calculated according to all coal seams mined out at the same time. The thickness of all coal seams is $18.1 \mathrm{~m}$.

\section{Analysis on calculated results}

a) Analysis on calculated results Extension height of WFFZ after each coal seam mined out.The height of WFFZ for each coal seam is calculated and shown in
Table 3. The larger value is decided as the final WFFZ for all 7 coal seams. The sketch of WFFZ is shown in Fig. 2. It is decided that according to this calculation program, the height of WFFZ is about $33.7 \mathrm{~m}$ above $8-1$ \# coal seam.

TABLE3. CALCULATED RESULTS OF WFFZ HEIGHT AFTER EACH COAL SEAM MINED OUT

\begin{tabular}{|c|c|c|}
\hline \multirow{2}{*}{ Coal seams } & \multicolumn{2}{|c|}{ Height of WFFZ /m } \\
\cline { 2 - 3 } & Formula One & Formula Two \\
\hline $8-1$ & 29.6 & 33.7 \\
\hline $8-2$ & 43.2 & 46.9 \\
\hline $8-3$ & 24.8 & 30 \\
\hline 9 & 35.8 & 39 \\
\hline 10 & 47.6 & 52.9 \\
\hline 12 & 37.9 & 41 \\
\hline 13 & 42.3 & 45.8 \\
\hline
\end{tabular}
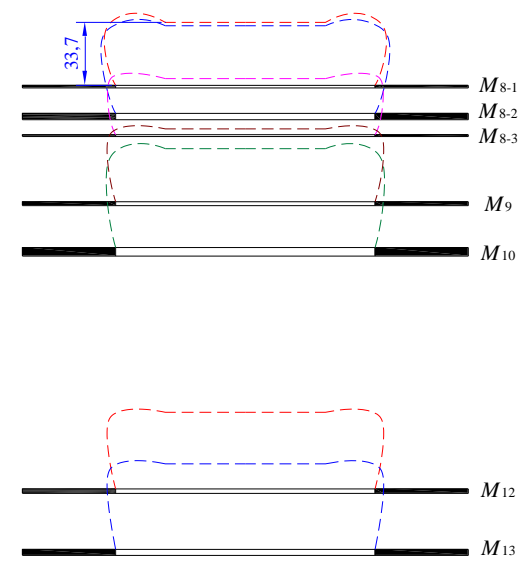

Fig.2. Sketch of WFFZ height after each coal seam mined out

b) Extension height of WFFZ after upper and lower groups coal seam mined out. The height of WFFZ for two groups is calculated and shown in Table 4. The larger value is decided as the final WFFZ for two group coal seams. It is decided that according to this calculation program, the height of WFFZ is about $81 \mathrm{~m}$ above $8-1$ \# coal seam when two group coal seams mined out orderly. The sketch of WFFZ is shown in Fig. 3.
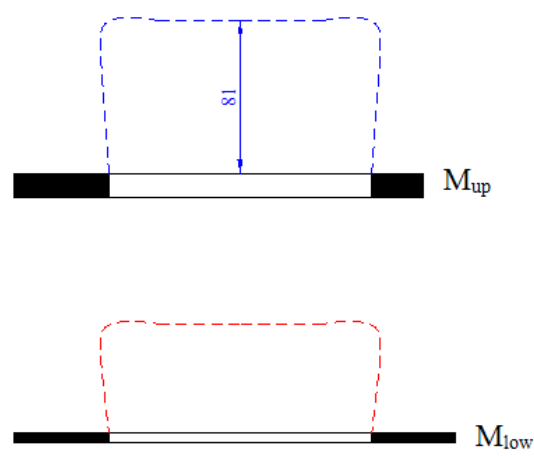

Fig.3. Sketch of WFFZ height after upper and lower groups coal seam mined out

TABle4. CAlculated RESUltS OF WFFZ HEIGHT AFTER UPPER AND LOWER GROUPS COAL SEAM MINED OUT

\begin{tabular}{|c|c|c|}
\hline \multirow{2}{*}{ Coal Seams } & \multicolumn{2}{|c|}{ Height of WFFZ/m } \\
\cline { 2 - 3 } & Formula One & Formula Two \\
\hline Lower group & 50.2 & 57.3 \\
\hline Upper group & 58.6 & 81 \\
\hline
\end{tabular}


c) Extension height of WFFZ after all coal seams mined out simultaneously. According to formula one, the height of WFFZ is calculated as $61.2 \mathrm{~m}$. According to formula two, the height of WFFZ is calculated as $95.1 \mathrm{~m}$. It is determined that the height of the WFFZ is $95.1 \mathrm{~m}$ when coal seams mined out at the same time. The sketch of WFFZ is shown in Fig. 4.

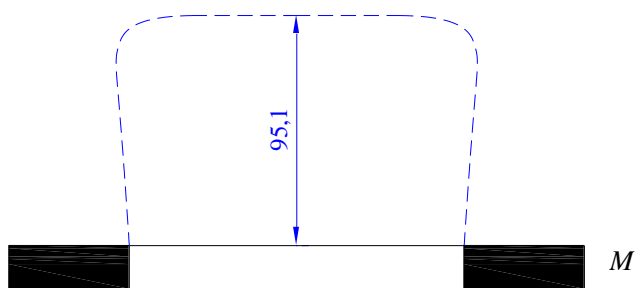

Fig.4. Sketch of WFFZ height after all coal seams mined out simultaneously

\section{Determination of WCRP}

When the outcrop of coal seam is covered by aquifers (Fig. 5), the waterproof coal (rock) pillars (short as WCRP) can be calculated as:

$$
H_{f}=H_{L}+H_{b}
$$

where $H_{f}$ is height of WCRP (m); $H_{L}$ is the maximum height of the WFFZ $(\mathrm{m}) ; H_{b}$ is thickness of protective layer $(\mathrm{m}) ; \alpha$ is the dip of coal seam $\left(^{\circ}\right)$.

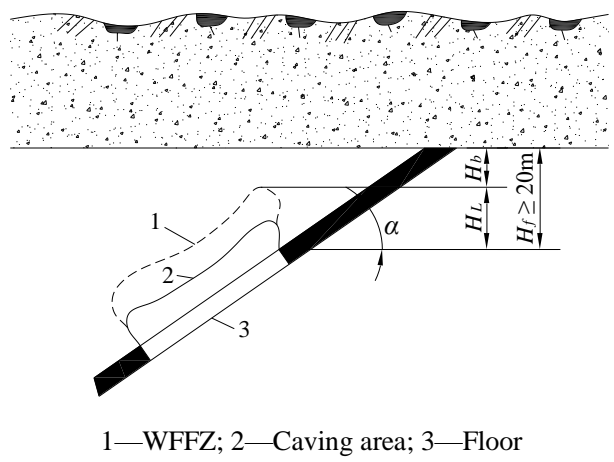

Fig.5. Sketch of WCRP

$H_{f}$, calculated by equation (1), must not be less than 20 m. $H_{L}$ and $H_{b}$ can be decided according to regulation rules [26].

The cumulative mining thickness of all 7 coal seams is $18.1 \mathrm{~m}$. According to geological condition in-situ, the average thickness of waterproof layer is $10.3 \mathrm{~m}$. Referring to regulation rules [26], thickness of protective layer $H_{b}$ can be taken as $4 A$. And,

$$
A=\sum M / n
$$

where $\sum M$ is cumulative mining thickness; $n$ is number of layers.

According to formula (2), $A$ is 2.59. Thus the thickness of waterproof layer is $10.36 \mathrm{~m}$.

a) WCRP determination after each coal seam mined out. After each coal seam mined out orderly, the height of the WFFZ reached $33.7 \mathrm{~m}$ above the upper group coal seam. According to formula (1), WCRP can be determined as:

$$
H_{f}=H_{L}+H_{b}=33.7+10.36=44.06 \mathrm{~m} .
$$

b) WCRP determination after upper and lower groups coal seam mined out. After the upper and lower group coal seams mined out, the height of the WFFZ reached $81.0 \mathrm{~m}$ above the upper group coal seam. According to formula (1), WCRP can be determined as:

$$
H_{f}=H_{L}+H_{b}=81.0+10.36=91.36 \mathrm{~m} .
$$

c) WCRP determination after all coal seams mined out simultaneously. After the upper and lower group coal seams mined out, the height of the WFFZ reached $95.1 \mathrm{~m}$ above the upper group coal seam. According to formula (1), WCRP can be determined as:

$$
H_{f}=H_{L}+H_{b}=95.1+10.36=105.46 \mathrm{~m} .
$$

\section{UDEC SIMULATION ANALYSIS ON THE EXTENSION HEIGHT OF WFFZ}

\section{A. Simulation program}

Due to large thickness of the whole model and less thickness of each coal seam, when all coal seams built in the same model, the WFFZ cannot be shown clearly in simulation results. Therefore, in order to highlight the WFFZ, two programs were used in this simulation.

a) Model of program 1. According to coal seams' occurrence, all coal seams can be divided into two groups: the upper group, which included 8-1 \#, 8-2 \#, 8-3 \#, 9 \#, 10 \# coal seams and the lower group, which included 12 \# and 13 \# coal seams. The upper and lower groups of coal seam are separated to establish two models (Fig. 6 and Fig. 7).

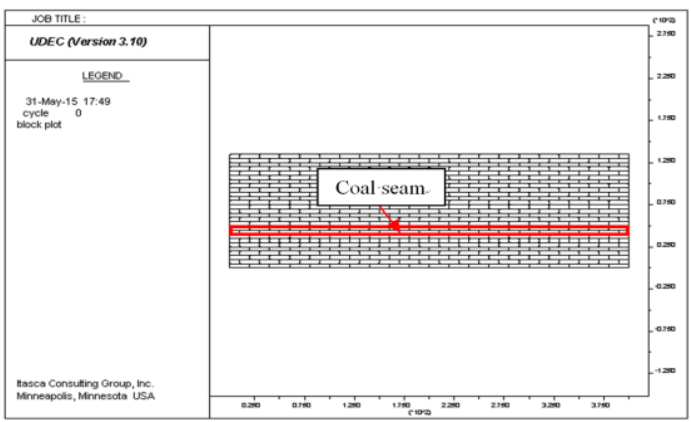

Fig.6. Lower group coal seam model in program 1

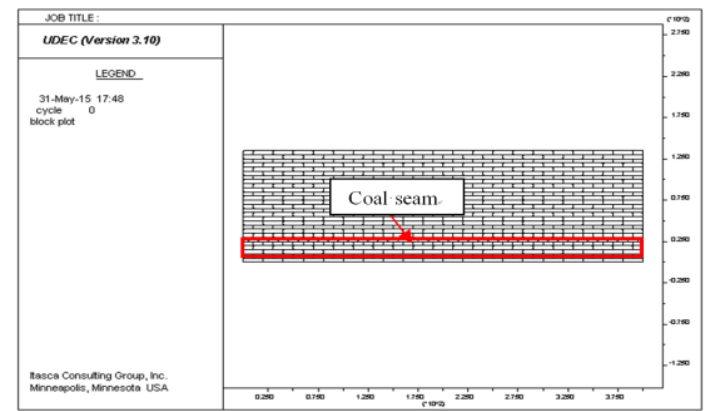

Fig.7. Upper group coal seam model in program 1

The total thickness of upper group is $12.5 \mathrm{~m}$. The model includes $20 \mathrm{~m}$ siltstones below the coal seam, $40 \mathrm{~m}$ fine sandstone, $50 \mathrm{~m}$ siltstone, $8 \mathrm{~m}$ mudstone, and the aquifer. About $457 \mathrm{~m}$ strata above the aquifer have not been established in the model. The $457 \mathrm{~m}$ strata were applied to the upper surface of the model in the form of 
vertical stress. The average volumetric weight density of the overlying strata is $23 \mathrm{kN} / \mathrm{m}^{3}$. The applied vertical stress was about 10.5 MPa. The strike length of the model was $400 \mathrm{~m}$. The thickness of lower group is $5.6 \mathrm{~m}$. The model includes $27 \mathrm{~m}$ coarse sandstone, $100 \mathrm{~m}$ glutenite. About $671 \mathrm{~m}$ strata have not been established in the model. The $671 \mathrm{~m}$ strata were also applied to the upper surface of the model in the form of vertical stress. The average volumetric weight density of the overlying strata is 23 $\mathrm{kN} / \mathrm{m}^{3}$. The applied vertical stress was about 15.4 MPa. The strike length of the model was $400 \mathrm{~m}$.

b) Model of program 2. All coal seams were considered as one seam and were mined out at the seam time. In the model (Fig. 8), the total thickness of the coal seam is $18.1 \mathrm{~m}$. The model includes $15 \mathrm{~m}, 40 \mathrm{~m}$ fine sandstone, $50 \mathrm{~m}$ siltstone, $8 \mathrm{~m}$ mudstone and the aquifer. About $457 \mathrm{~m}$ strata above the aquifer have not been established in the model. The $457 \mathrm{~m}$ strata were applied to the upper surface of the model in the form of vertical stress. The average volumetric weight density of the overlying strata is $23 \mathrm{kN} / \mathrm{m}^{3}$. The applied vertical stress was about 10.5 MPa. The strike length of the model was $400 \mathrm{~m}$.

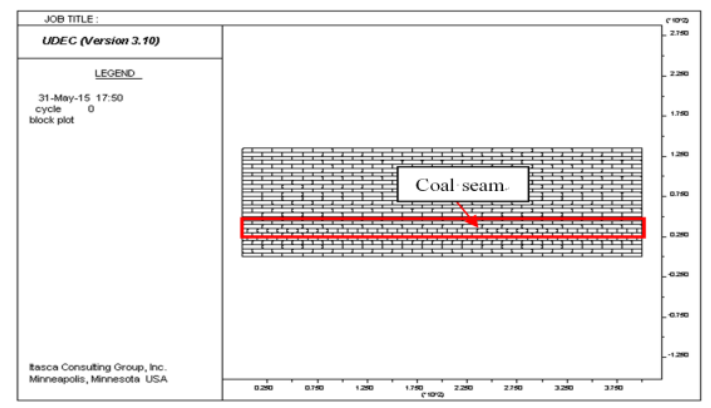

Fig.8. Whole coal seam model in program 2

In simulation, $50 \mathrm{~m}$ boundary pillars were left on the left and right sides of the model. Namely, in the model, along the strike direction, the advancing length was $300 \mathrm{~m}$. In program 1, after lower group coal seam mined out, the height of WFFZ was analyzed to evaluate if it could extend to the upper group coal seam or not. If there was no effect, the upper group coal seam could be mined out. Then the height of the WFFZ during upper group coal seam mining is taken as the height of the WFFZ of program 1.

\section{B. Analysis on numerical simulation results}

a) Results of program 1. After lower group coal seam mined out, the displacement of the overburden strata was shown in Fig. 9. The sketch of the 0-displacement boundary line was shown in Fig. 10. It can be seen that after lower group coal seam mined out, the 0-displacement boundary extended to $21.2 \mathrm{~m}$ above the coal seam. There is no motion in the strata above the 0 displacement boundary. The mined-out area could be considered as the height of the caving zone and the height of the WFFZ. Therefore, when the lower group coal seam was mined out, the WFFZ extended to $21.2 \mathrm{~m}$ above the lower group coal seam and could not reach the upper group coal seam.

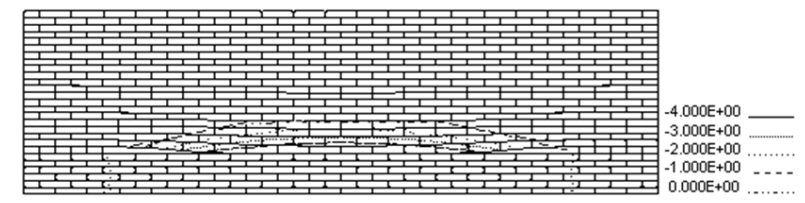

Fig.9. Displacement of overburden strata after lower group coal seam mined out

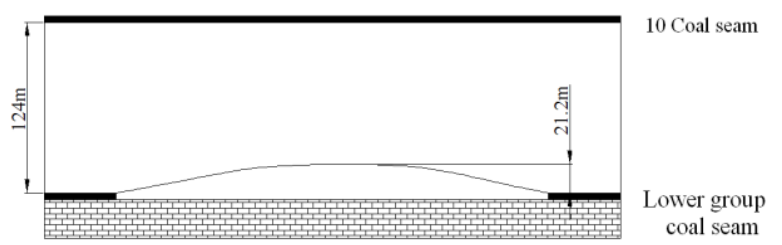

Fig.10. Sketch of 0-displacement boundary line after lower group coal seam mined out

After upper group coal seam mined out, the displacement of the overburden strata was shown in Fig. 11. The sketch of the 0-displacement boundary line was shown in Fig. 12. It can be seen that after upper group coal seam mined out, the 0-displacement boundary extended to $46.0 \mathrm{~m}$ above the coal seam. Namely, in program 1, the WFFZ extended to $46.0 \mathrm{~m}$ above the upper group coal seam.

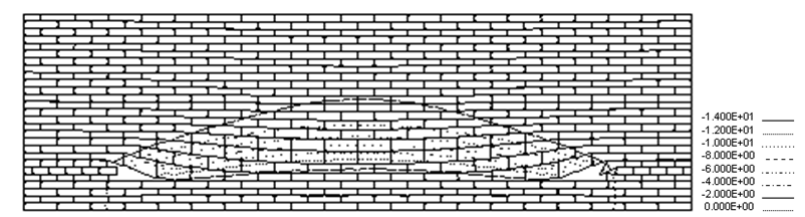

Fig.11. Displacement of overburden strata after upper group coal seam mined out

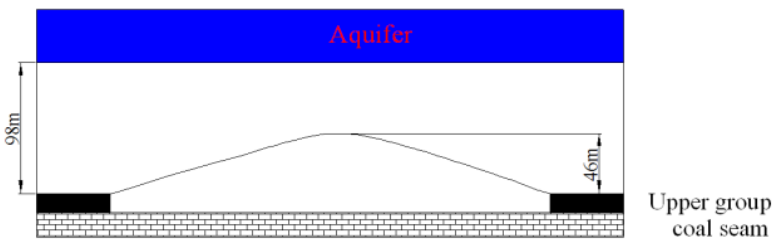

Fig.12. Sketch of 0-displacement boundary line after upper group coal seam mined out

b) Results of program 2. After all coal seams mined out, the displacement of the overburden strata was shown in Fig. 13. The sketch of the 0-displacement boundary line was shown in Fig. 14. It can be seen that after all coal seams mined out, the 0-displacement boundary extended to $76.0 \mathrm{~m}$ above $8-1$ \# coal seam. Namely, in program 2, the WFFZ extended to $76.0 \mathrm{~m}$ above the 8-1 \# coal seam.

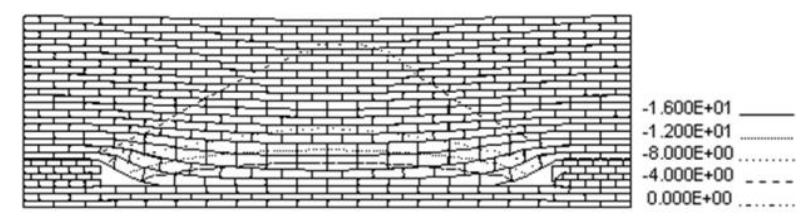

Fig.13. Displacement of overburden strata after all coal seams mined out

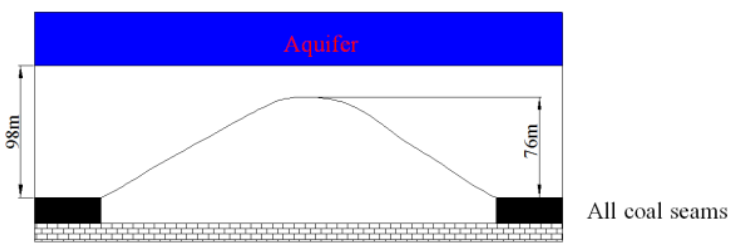

Fig.14. Sketch of 0-displacement boundary line after all coal seams mined out 


\section{Determination of WCRP}

After the upper and lower group coal seams mined out in program 1, the height of the WFFZ reached $46.0 \mathrm{~m}$ above the upper group coal seam. According to formula (1), WCRP can be determined as:

$$
H_{f}=H_{L}+H_{b}=46+10.36=56.36 \mathrm{~m} .
$$

After all coal seams mined out in program 2, the height of the WFFZ reached $76.0 \mathrm{~m}$ above 8-1\# coal seam. According to formula (1), WCRP can be determined as:

$$
H_{f}=H_{L}+H_{b}=76+10.36=86.36 \mathrm{~m} .
$$

Combined with simulation results of programs 1 and 2, the height of the WFFZ for coal mining in the upper and lower groups was $46 \mathrm{~m}$, and the height of WFFZ when all coal seams mined out at the same time was $76 \mathrm{~m}$. According to formula (1), the heights of the WCRP in programs 1 and 2 were determined as $56.36 \mathrm{~m}$ and 86.36 $\mathrm{m}$, respectively.

\section{PHYSICAL SIMULATION ANALYSIS ON THE EXTENSION HEIGHT OF WFFZ}

\section{A. Physical model design}

Experiment frame is $190 \mathrm{~cm}$ in length and $20 \mathrm{~cm}$ in width. According to the size of the frame, combined with the in situ coal seam occurrence conditions, the geometric ratio of the physical model was decided as $1 / 500$. Namely the geometrical ratio of the physical model is $C_{11}=1 / 500$ The bulk density ratio was chosen as $C_{\gamma 1}=1 / 1.5$. Then the motion ratio was got as $C_{\mathrm{t} 1}=1 / 22.4$; the elastic modulus ratio was gained as $C_{\mathrm{E} 1}=1 / 750$, and the stress ratio was gained as $C_{\mathrm{P} 1}=1 / 750$.

As same as the numerical simulation program 1, all coal seams were divided into upper group, which included 8-1 \#, 8-2 \#, 8-3 \#, 9 \#,10 \# coal seams and lower group, which included 12\# and 13\# coal seams. The thickness of upper group is $12.5 \mathrm{~m}$. The thickness of lower group is $5.6 \mathrm{~m}$. The distance between two groups was $202.9 \mathrm{~m}$. Due to small size of the experimental frame, strata in the physical model could not include all strata above aquifer. According to the occurrence of coal seams, it was determined that there were $230 \mathrm{~m}$ strata that have not included in the physical model. The $230 \mathrm{~m}$ strata were applied to the upper surface of the model in the form of loads. The physical model was shown in Fig. 15.

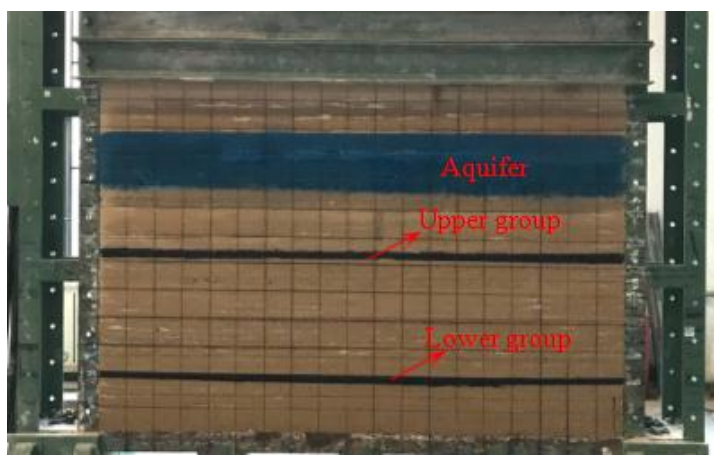

Fig.15. Physical model

In this model, the upper and lower group coal seams were marked with black paint and the aquifer was marked with blue paint. At the same time, for deformation monitoring of the overburden strata, $10 \mathrm{~cm} \times 10 \mathrm{~cm}$ grid line was put on the front of the model. The test was conducted in two steps. First, the upper group coal seam was mined to observe the extension of the WFFZ. After upper group mined out and the overlying strata stabilized, the lower group coal seam was mined to observe the extension of the WFFZ. In order to reduce the effect of boundary, in left and right boundaries, $20 \mathrm{~cm}$ coal pillar was left for the protective pillar. The total length of the model was $190 \mathrm{~cm}$. Thus the mining length of the model was $150 \mathrm{~cm}$.

\section{B. Analysis on physical simulation results}

a) Results after upper group coal seam mined out. The caving of overlying strata was shown in Fig. 16. When the working face was advanced $150 \mathrm{~cm}$, the height of caving strata extended to $8.0 \mathrm{~cm}$ above the coal seam, which was equal to $40 \mathrm{~m}$ in-situ. The height of the coal seam was $12.5 \mathrm{~m}$. Therefore, the mining-to-falling ratio was 3.2 , which was accordance with the production experience. There was about $14.0 \mathrm{~cm}$ from the top of caving zone to aquifer. Namely, in-situ production, there was about 70.0 $m$ WCRP between mining influenced zone and the aquifer.

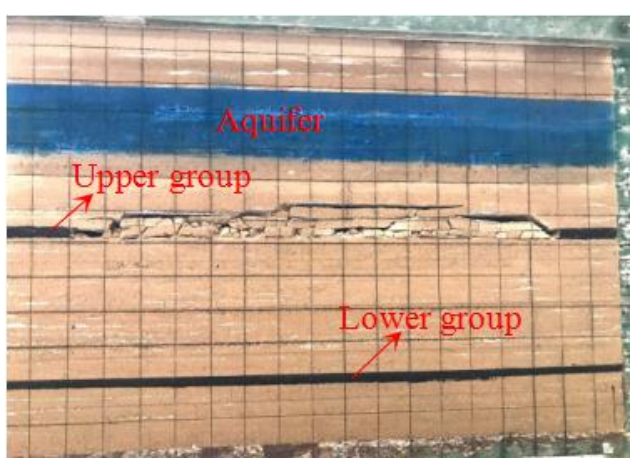

Fig.16. The caving of overlying strata after upper group coal seam mined out

b) Results after lower group coal seam mined out. The caving of overlying strata was shown in Fig. 17.

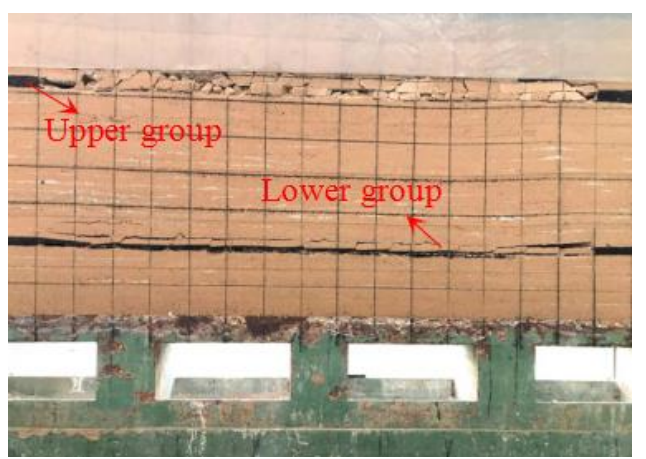

Fig.17. The caving of overlying strata after lower group coal seam mined out

When the working face was advanced $150 \mathrm{~cm}$, the height of caving strata extended to $17.5 \mathrm{~cm}$ above the coal seam. Above the caving zone, there was no fractured zone in the overlying strata. There were only caving zone and bending zone. Affected by the bending and subsidence of overburden strata induced by lower coal seam mining, 
there was only a slight bending subsidence in the strata of upper goaf. This effect has not extended to the strata above the caving zone. Namely, there was no mining influence on the aquifer.

Through physical simulation, it was got that after two groups coal seam mined out, the WFFZ extended to the height of $40 \mathrm{~m}$ above 8-1 \# coal seam and the WCRP was $70.0 \mathrm{~m}$ to the aquifer.

\section{CONCLUSION}

In coal seams mining in No.1 mine of Tashendian area, three methods of theoretical analysis, UDEC numerical simulation, and physical simulation test were used in this research to analyze the extension height of WFFZ and the height of WCRP. By calculation, it was obtained that, after each coal seam mined out, the height of WFFZ is about $33.7 \mathrm{~m}$ above 8-1 \# coal seam, and the size of WCRP greater than $44.06 \mathrm{~m}$ was reasonable; after upper and lower groups coal seam mined out, the height of WFFZ is about $81 \mathrm{~m}$ above 8-1 \# coal seam, and the size of WCRP greater than $91.36 \mathrm{~m}$ was reasonable; after all coal seams mined out simultaneously, the height of WFFZ is about $95.1 \mathrm{~m}$ above 8-1 \# coal seam, and the size of WCRP greater than $105.46 \mathrm{~m}$ was reasonable. By numerical simulation, it was obtained that, after upper and lower groups coal seam mined out, the height of WFFZ is about $46.0 \mathrm{~m}$ above $8-1$ \# coal seam, and the size of WCRP greater than $56.36 \mathrm{~m}$ was reasonable; after all coal seams mined out simultaneously, the height of WFFZ is about 76.0 m above 8-1 \# coal seam, and the size of WCRP greater than $86.36 \mathrm{~m}$ was reasonable; By physical simulation, it was obtained that, after upper and lower groups coal seam mined out, the height of WFFZ is about $40.0 \mathrm{~m}$ above 8-1 \# coal seam. And the WCRP was about $70.0 \mathrm{~m}$ between and the aquifer. In situ production, each coal seam was mined out orderly. In this research, two groups coal seam mined out orderly and all coal seams mined out simultaneously were two extreme states in analysis, data based on these two states were bigger than reality.

\section{ACKNOWLEDGEMENT}

This study was supported by the National Natural Science Foundation of China [grant numbers 51604164] and by the program of youth teacher growth plan in Shandong province.

\section{REFERENCES}

[1] Peng Wenqing, Wang Weijun, and Li Qingfeng, "Reasonable width of waterproof coal pillar under the condition of different fault dip angles," Journal of Mining \& Safety Engineering, vol. 26, no. 2, pp. 179-182, 2009.

[2] Meng Zhaoping, Gao Yanfa, Lu Aihong, and et al., "Water inrush risk evaluation of coal mining under quaternary alluvial water and reasonable design method of waterproof coal pillar," Journal of Mining \& Safety Engineering, vol. 30, no. 1, pp. 24-29, 2013.

[3] Wang Lianguo, Wang Zhansheng, Huang Jihui, and et al., "Prediction on the height of water-flowing fractured zone for shallow seam covered with thin bedrock and thick windblown sands," Journal of Mining \& Safety Engineering, vol. 29, no. 5, pp. 607-612, 2012.

[4] Liu Zhijun, and Hu Yaoqing, "Solid-liquid coupling study on water inrush through faults in coal mining above confined aquifer," Journal of China Coal Society, vol. 32, no. 10, pp. 1046-1050, 2007.

[5] Li Yongming, Liu Changyou, and Huang Bingxiang, "Influence of key stratum on waterproof coal pillar size in steep seam," Journal of Mining \& Safety Engineering, vol. 29, no.2, pp. 226-231, 2012.

[6] Liu Bo, He Lei, and Luo Liping, "Numerical modeling on fluid-solid coupling for the waterproof coal pillar design," Journal of Mining \& Safety Engineering, vol. 26, no. 4, pp. 445-454, 2009.

[7] Yin Shangxian. "Numerical simulation of influence of water barrier pillars for subsided column on rock failure in mining process," Journal of China Coal Society, vol. 31, no. 2 pp. 179-182, 2006.

[8] Chen Ronghua, Bai Haibo, and Feng Meimei, "Determination of the height of water flowing fractured zone in overburden strata above fully-mechanized top-coal caving face," Journal of Mining \& Safety Engineering, vol. 23, no. 2, pp. 220-223, 2006.

[9] He Guicheng, Xiao Fuguo, Zhang Zhijun, and et al., "Prediction of the height of the transmissive fractured belt of a mining stope under aquifer in Kang jiawan Mine," Journal of Mining \& Safety Engineering, vol. 28, no. 1, pp. 122-126, 2011.

[10] Yang Yanguo, Wang Jun, and Yu Yongjiang, "Effects of different coal safe mining sequence under river on height of water flowing fracture zone," Journal of China Coal Society, vol. 40, no. sup 1, pp. $27-32,2015$

[11] Jia Jianqing, Wang Hongtu, Hu Guozhong, and et al., "Methods of retaining water barrier and its stability analysis of steep working face," Journal of China Coal Society, vol. 34, no. 3, pp. 315-319, 2009.

[12] Xu Jialin, Wang Xiaozhen, Liu Wentao, and et al, "Effects of primary key stratum location on height of water flowing fracture zone," Chinese Journal of Rock Mechanics and Engineering, vol. 28, no. 2, pp. 380-385, 2009.

[13] Zhu Wancheng, Wei Chenhui, Zhang Fuzhuang, and et al., "Investigation of water inrush from karst subsidence column by using a coupled hydro mechanical model," Chinese Journal of Underground Space and Engineering, vol. 5, no. 5, pp. 928-933, 2009.

[14] Tu Min, Gui Herong, Li Minghao, and et al., "Testing study on mining of water roof coal pillars in thick loose bed and thick coal seam under ultrathin overlying strata," Chinese Journal of Rock Mechanics and Engineering, vol. 23, no. 20, pp. 3494-3497, 2004.

[15] Ma Yajie, Wu Qiang, Hong Yiqing, and et al., "Deformation analysis of covering rock masses as mining steep-inclined coal seam and its application," Journal of China Coal Society, vol. 34, no. 3, pp. 320-324, 2009

[16] Xu Yanchun, "Design methods of the effective water-resisting thickness for the protective seam of the water barrier in fully-caving mechanized coal mining," Journal of China Coal Society, vol. 30, no. 3, pp. 305-308, 2005.

[17] Shi Longqing, Xin Hengqi, Zhai Peihe, and et al., "Calculating the height of water flowing fracture zone in deep mining," Journal of China University of Mining \& Technology, vol. 41, no. 1, pp. 37-41, 2012.

[18 Li Zhenhua, Xu Yanchun, Li Longfei1, and et al., "Forecast of the height of water flowing fractured zone based on BP neural networks," Journal of Mining \& Safety Engineering, vol. 32, no. 6, pp. 905-910, 2015.

[19] Zhang Jianmin, Zhang Kai, Cao Zhiguo, and et al., "Mining-bursting simulation and height calculation method for conducting-water fractured zone," Journal of China Coal Society, vol. 42, no. 6 , pp. $1557-1564,2017$

[20] Yang Guoyong, Chen Chao, Gao Shulin, and et al., "Study on the height of water flowing fractured zone based on analytic hierarchy process and fuzzy clustering analysis method," Journal of Mining \& Safety Engineering, vol. 32, no. 2, pp. 206-212, 2015.

[21] Li Quansheng, Ju Jinfeng, Cao Zhiguo, and et al., "Suitability evaluation of underground reservoir technology based on the discriminant of the height of water conduction fracture zone," Journal of China Coal Society, vol. 42, no. 8, pp. 2116-2124, 2017.

[22] Zhang Hongwei, Zhu Zhijie, Huo Bingjie, and et al., "Water flowing fractured zone height prediction based on improved FOA-SVM," China Safety Science Journal, vol. 23, no. 10, pp. 9-14.

[23] Xu Jialin, Zhu Weibing, and Wang Xiaozhen, "New method to predict the height of fractured water-conducting zone by location of key strata," Journal of China Coal Society, vol. 37, no. 5, pp. 762-769.

[24] Gao Baobin, Liu Yunpeng, Pan Jiayu, and et al., "Detection and analysis of height of water flowing fractured zone in underwater mining," Chinese Journal of Rock Mechanics and Engineering, vol. 33 
no. supp 1, pp. 3384-3390, 2014.

[25] Sun Yunjiang, Zuo Jianping, Li Yubao, and et al., "Micro-seismic monitoring on fractured zone and water inrush mechanism analysis of deep mining above aquifer in Xingdong coalmine," Rock and Soil
Mechanics, vol. 38, no. 8, pp. 2235-2342, 2017.

[26] Jin Liansheng, and Mou Jinsuo, Specification for coal pillar and coal mining in buildings, water bodies, railways and main roadway, 2017, Beijing: China Coal Industry Publishing House. 
